\title{
Insights Eu sorption onto kaolinite
}

\author{
ANNA SEMENKOVA, PHD $^{1}$, PARVEN VERMA ${ }^{2,3}$, \\ VICTORIA KRUPSKAYA ${ }^{4}$, ANNA ROMANCHUK ${ }^{1}$ AND \\ STEPAN KALMYKOV ${ }^{1}$ \\ ${ }^{1}$ Lomonosov Moscow State University \\ ${ }^{2}$ Bhabha Atomic Research Centre, \\ ${ }^{3}$ Homi Bhabha National Institute \\ ${ }^{4}$ Institute of Geology of Ore Deposits, Petrography, Mineralogy \\ and Geochemistry (IGEM) RAS \\ Presenting Author: annamik88@rambler.ru
}

Nowadays, the isolation of radioactive waste (RW) from the biosphere is one of the main problem of nuclear industry. In accordance with the requirements of radiation safety geological isolation of RW a multi-barrier safety system should be build, and natural clays are considered to be one of the most promising components. A lot of works are devoted to radionuclides interaction with bentonite clays. In this work we focused on kaolinite, which is a common impurity in bentonites and is also widespread in soils. The Eu(III) sorption behavior on kaolinite samples with different mineral composition (containing admixture of montmorillonite, $\mathrm{TiO}_{2}$ and purified) was studied. According to previous proceedings, the binding of lanthanides to clay surface occurs in two pathways: by the mechanism of ionic exchange and by complexation with surface groups [1]. Varying the experimental conditions made it possible to evaluate the contribution of different interaction mechanisms to europium sorption on kaolinites. In addition, the influence of the europium binding mechanism on its desorption was determined.

Various techniques, e.g. XRD, XRF, BET absorption, etc. were used to clay characterization. Batch sorption and desorption experiments were performed under various $\mathrm{pH}$, ionic strengths and radionuclide concentrations $\left(10^{-11}-10^{-6} \mathrm{M}\right)$, thermodynamic modeling of the resulting data was carried out.

It was shown, that background electrolyte strongly affects the $\mathrm{Eu}(\mathrm{III})$ uptake. At low ionic strengths $(0.01 \mathrm{M})$ and low $\mathrm{pH}$ ionic exchange mechanism dominates, while at high $\mathrm{pH}(\mathrm{pH}>6)$ and high ionic strengths $(1 \mathrm{M})$ the complexation mechanism prevails. Depending on the interaction mechanism, significant differences in Eu(III) desorption were observed.

It's necessary to combine ion exchange and surface complexation reactions to create adequate $\mathrm{Eu}(\mathrm{III})$ sorption model. Since the constant of $\mathrm{Eu}(\mathrm{III})$ ion exchange onto clays differs from study to study, additional experiments were performed to determine this impact on $\mathrm{Eu}(\mathrm{III})$ sorption on kaolinite.

This work was supported by the Russian Science Foundation (project 20-73-00135).

\section{References}

[1] Verma, P. K. et al. (2019), Appl. Clay Sci. 175, 1-8 . 